\begin{tabular}{r|l|l|l}
$\begin{array}{c}\text { Case Reports in } \\
\text { Oncology }\end{array}$ & $\begin{array}{l}\text { Case Rep Oncol 2010;3:480-488 } \\
\text { DOl: 10.1159/000323204 }\end{array}$ & $\begin{array}{l}\text { Published online: } \\
\text { December 17, 2010 }\end{array}$ & $\begin{array}{l}\text { @ 2010 S. Karger AG, Basel } \\
\text { ISSN 1662-6575 } \\
\text { www.karger.com/cro }\end{array}$ \\
\hline
\end{tabular}

\title{
Cetuximab Concomitant with Second-Line Radiation Therapy in Patients with Locally Advanced Recurrent Squamous Cell Head and Neck Cancer
}

\author{
Muge Akmansu $^{\mathrm{a}} \quad$ Suleyman Buyukberber ${ }^{\mathrm{b}} \quad$ Sevilay Iren $^{\mathrm{a}}$ \\ Umut Demirci $^{\mathrm{b}} \quad$ Gul Kanyilmaz $^{\mathrm{a}} \quad$ Ugur Coskun $^{\mathrm{b}}$ \\ Huseyin Bora ${ }^{\mathrm{a}}$
}

Departments of a Radiation Oncology and ${ }^{b}$ Medical Oncology, Gazi University

School of Medicine, Ankara, Turkey

\section{Key Words}

Cetuximab · Head and neck carcinoma - Irradiation - Radiotherapy · Recurrence

\begin{abstract}
We presented 9 recurrent head and neck carcinoma patients. Priorly all of them had received radiochemotherapy. We used cetuximab and irradiation concomitantly. Overall survival analysis of the patients was performed using the Kaplan-Meier method on SPSS version 15.0. Based on this calculation, mean follow-up duration is 12.8 months. Mean survival time is 19.8 months and annual mean survival rate is $59.3 \%$.
\end{abstract}

\section{Introduction}

Head and neck cancers constitute almost $6 \%$ of all cancers worldwide. In Europe, 150,000 cases of newly diagnosed head and neck cancer are reported each year. It is well known that prognosis of patients with inoperable local recurrent squamous cell head and neck cancer (SCHNC) is considerably poor. There are limited treatment options available for these patients, including second-line radiotherapy (RT), chemotherapy (CT), chemoradiotherapy (CRT) or supportive care alone [1]. While the average survival time of untreated patients is only 4 months, response rates increase by $30-40 \%$ and survival reaches 6-9 months in patients administered platinum-based combination therapy. Mean survival does not exceed 100 days in patients with progressing disease while undergoing CT [2]. Epidermal growth factor receptor (EGFR) is a member of the human epidermal receptor (HER) family. Abnormal levels of EGFR expression can be seen in $80-100 \%$ of 
head and neck tumors. There is a positive correlation between the level of EGFR expression and bad prognosis, metastatic disease and short survival times. Cetuximab (CTX) is an IgG1 monoclonal antibody which inhibits binding of ligands to EGFR [3]. Recent studies have shown that concomitant administration of CTX with RT results in significantly better local-regional control compared to RT alone in patients with locally advanced SCHNC $[4,5]$. Synergy of CTX with antitumor effects of cisplatin has been demonstrated in xenograft models [6]. Accordingly, increased response and survival rates were reported in studies using CTX concomitant with cisplatin/carboplatin in patients with platinum-based CT-resistant local recurrent SCHNC [7-9]. There are no studies in the literature demonstrating that the efficacy of CTX concomitant with RT in locally advanced disease also applies to locally advanced recurrent disease. Based on this, we evaluated the data on CTX administration concomitant with second-line RT in patients with locally advanced recurrent SCHNC (except nasopharynx) whose disease progressed despite CT or who could not be administered platinum-based CT. None of the patients had distant metastasis.

\section{Patients and Methods}

\section{Patient Characteristics}

Nine patients [mean age 55 (42-65) years, 7 males and 2 females] with locally advanced recurrent SCHNC were admitted to our clinics between May 2008 and May 2010. On admission, all patients had a Karnofsky performance score between 80 and 90 . Two patients had carcinoma of the larynx with recurrence in tracheostomy, 2 had carcinoma of the larynx with neck metastasis, 2 had carcinoma of the lip with neck metastasis, 2 had carcinoma of the mouth base with recurrence and 1 patient had carcinoma of the tongue base with neck metastasis. According to the regions of primary disease, all patients had previously received curative doses of RT concomitant with cisplatin in our clinics. Following primary treatment, based on the local recurrence observed in these patients, 2 underwent salvage surgery, while the others received various combinations of systemic treatments including cisplatin, methotrexate and taxanes for different durations. One patient was on imatinib treatment, due to leukemia, and could not tolerate CT. CTX concomitant with second-line RT was administered to patients who did not show distant metastasis on positron emission tomography/computed tomography scans.

\section{Radiotherapy}

Tomography scans with 5-mm slice intervals were performed for treatment planning. 3-D conformal RT was planned based on the tomography scans and considering the tolerance doses of critical organs such as the spinal cord and mandibula. Computed tomography, positron emission tomography/ computed tomography scans or MRI was used to determine target volume. Treatment was administered by a linear accelerator device using the energies of photons and electrons. RT doses were between 20 and $70 \mathrm{~Gy} ; 4$ of 5 patients with neck metastases received $20 \mathrm{~Gy}, 1$ received $30 \mathrm{~Gy}, 1$ of 2 patients with carcinoma of the mouth base received $40 \mathrm{~Gy}, 1$ received $20 \mathrm{~Gy}$ and 2 patients with recurrence in tracheostomy received 70 Gy of RT.

\section{CTX Administration}

CTX was administered to all patients as a $400 \mathrm{mg} / \mathrm{m}^{2}$ loading dose before RT and a $250 \mathrm{mg} / \mathrm{m}^{2}$ weekly maintenance dose. Four patients received 4 cycles and 5 patients received 6 cycles of CTX concomitant with RT. 


\section{Side Effects and Tolerability}

Overall, CTX concomitant with RT was well tolerated by the patients. Skin reactions, known to be the most common side effect of CTX, were observed in all patients in various grades. During RT, 4 patients had grade 2 and 5 patients had grade 3 toxicity according to the National Cancer InstituteCommon Terminology Criteria for Adverse Events (NCI-CTCAE) (table 1). An acneiform rash outside of the RT regions and frequently around the upper chest wall, upper back and gluteal region was observed following the second week of treatment. The grade of the rash based on the NCI-CTCAE was grade 1 in 5 patients and grade 2 in 4 patients (table 2 ).

Xerosis cutis was seen in all patients in various grades. Paronychia-like reactions were observed in 2 of 5 patients receiving 6 cycles of CTX. No electrolyte imbalance was seen in these cases.

\section{Statistical Analysis}

Five patients died 3, 5, 9, 10, and 18 months after completion of treatment, while the remaining 4 patients are being followed up during the $3 \mathrm{rd}$, 5th, and 12th month of treatment. Overall survival analysis of the patients was performed using the Kaplan-Meier method on SPSS version 15.0. Based on this calculation, mean follow-up duration is 12.8 months. Mean survival time is 19.8 months and the annual mean survival rate is $59.3 \%$.

\section{Discussion}

Local-regional recurrence in SCHNC patients is still considered as the most important failure of treatment. More than $50 \%$ of the patients die because of local-regional recurrence. In recurrences and/or metastatic diseases, available treatment options are limited by the previously administered curative treatments. Rescue treatments are still popular and important as a standard of care. In the literature, there are no significant clinical trials including a high number of patients which prove the efficacy of second-line $\mathrm{CT}$ in SCHNC patients whose disease progresses following platinum-based CT.

Accordingly, there is no commonly accepted treatment regimen available for this patient population [10]. While the first option for second-line CT almost always includes platinum-based agents, clinical efficacy of treatments including a combination of vinorelbine, docetaxel, paclitaxel and pemetrexed or third-generation cytotoxic agents such as irinotecan is also discussed [1]. A review of retrospective analyses shows that in patients with recurrent and/or metastatic disease who receive single-agent CT such as cisplatin, methotrexate, 5-fluorouracile (5-FU) and bleomycine, response rates are between 15 and 30\%, with mean survival time being 3-5 months $[11,12]$. Patients who cannot tolerate single-agent CT have difficulties in tolerating combination therapies with the addition of new agents as well. Mean survival time with combination CT is around 69 months. Cisplatin/5-FU (PF) is the most widely used combination regimen in patients with recurrent and/or metastatic SCHNC. In a phase 3 study of 249 patients by Jacobs et al. [13], PF combination was compared with cisplatin alone and 5-FU alone, and response rates were observed as $32 \%$ in PF, $17 \%$ in cisplatin and $13 \%$ in $5-\mathrm{FU}$ arms $(\mathrm{p}=0.035)$, although overall survival was not significantly different between the 3 arms. In the intergroup E1395 study [14] of the Eastern Cooperative Oncology Group including 218 patients, paclitaxel + cisplatin (PP) combination was compared with PF combination, and response rates of 27 and $26 \%$, respectively, were found. Mean survival time was 8.1 months in the PP arm and 8.7 months in the PF arm. The frequencies of grade 3-4 toxicities were similar between both groups. Based on these results, PP combination can be considered as an alternative to PF combination. In the phase 2 study by Janinis et al. 
[15] comparing the combination of PF with docetaxel with PF combination, mean survival time in the docetaxel arm was 11 months, but febrile neutropenia was observed in $15 \%$ of the patients. In a phase 2 study by Benasso et al. [16] including 47 patients, mean survival time with paclitaxel + PF combination was 7.9 months, but grade 3-4 neutropenia was seen in $48 \%$ of the patients.

These results show that independent of which drugs are combined, combination treatment overall results in better survival compared to single-agent regimens with methotrexate, cisplatin or 5-FU. Combination CT should be preferred, especially in young and symptomatic patients with good performance status, to decrease the symptoms of disease [1]. EGFR is a member of the HER family and is a transmembrane receptor. Following binding of ligands, the receptor undergoes autophosphorylation and activates tyrosine kinases. Autophosphorylation results in activation of intracellular pathways that stimulate cancer proliferation, inhibition of apoptosis, activation of metastases and invasion, as well as tumor neovascularization. Abnormal levels of EGFR expression have been demonstrated in $80-100 \%$ of head and neck tumors. There is a positive correlation between the level of EGFR expression and bad prognosis, metastatic disease and low survival time.

CTX is an IgG1 monoclonal antibody that binds to the extracellular chain of EGFR and maintains its activation, while preventing autophosphorylation and tyrosine kinase activation. Consequently, it blocks the rest of the pathway and the occurrence of consecutive events [17]. Synergy of CTX with the antitumor effects of cisplatin has been demonstrated in xenograft models [6]. The addition of CTX to CT in patients with recurrent and persistent SCHNC has been shown to cause significant increase in response rate without increasing toxicity.

In a phase 2 study by Baselga et al. [8] comparing platinum-based CT + weekly CTX with platinum-based CT alone in 96 patients with platinum-resistant SCHNC, mean survival time in CT + CTX and CT alone arms was 183 days and 85 days, respectively. In a phase 3 study performed by Vermorken et al. [9] in patients with recurrent and/or metastatic head and neck cancer, the addition of CTX to standard dose cisplatin + 5-FU CT resulted in an increase of 2.7 months' mean survival time and a $20 \%$ decrease in the risk of death. In a study by Bonner et al. [4] comparing the local-regional control upon concomitant use of CTX with RT to RT alone in patients with locally advanced SCHNC, the results were significantly in favor of the RT + CTX arm. Mean survival time was 49 months in the RT + CTX arm, but 29.3 months in the RT alone arm. The effects of CRT and CTX + RT in patients with locally advanced head and neck cancer were compared in the RTOG study performed by Caudell et al. [18]. The 3-year local-regional control rate in the CTX + RT arm and the CRT arm was 70.7 and $74.7 \%$, respectively, with the difference being statistically insignificant. The 3 -year distant metastases-free survival rate was similar, $92.4 \%$ in the CTX + RT arm and $86.6 \%$ in the CRT arm. The 3-year diseasefree survival rate was $76.5 \%$ in the CRT arm and $78.6 \%$ in the CTX + RT arm, without any statistically significant difference between both groups. Although CTX + RT seems superior to today's standard CRT regimens according to indirect comparisons performed between patients with locally advanced disease, there are still no phase 3 studies comparing these 2 regimens directly. In the ongoing phase 3 randomized RTOG 0522 study, the efficacy of the addition of CTX to CRT in naive locally-advanced SCHNC patients is being investigated. 
Second-line radiation is a common rescue therapy in patients with recurrent and/or metastatic SCHNC. As in primary treatment, the administration of CT concomitant with $\mathrm{RT}$ in recurrent and/or metastatic disease increases local-regional control and survival time. Although concomitant treatment commonly involves platinum-based chemotherapeutic agents, treatment outcomes are not always satisfactory. The addition of taxanes to the treatment regimens of patients with good performance status leads to high toxicity despite the increase in 2-year survival rates, compared to a $5-45 \%$ increase seen with cisplatin concomitant with RT [10]. In their study including 38 patients with recurrent unresectable SCHNC, Kramer et al. [19] administered cisplatin and paclitaxel concomitant with split-course radiation and reported a 2-year survival rate of $35 \%$ and a 1 -year disease-free survival rate of $33 \%$. Treatment-associated morbidity rates were acceptable. Five-year local-regional control and overall survival in 29 patients with recurrent or second primary SCHNC who underwent hyperfractionated regimens concomitant with gemcitabine, paclitaxel and 5-FU were 26 and 45\%, respectively; however, the ratio of late toxicities secondary to RT was relatively high [20]. Although it is difficult to derive any conclusions from small patient populations, better tumor control and higher survival rates have been reported with regimens including CT involving taxanes concomitant with second-line radiation; these advantages are, however, accompanied by significantly increased rates of acute and late morbidities. There are no studies in the literature demonstrating that the efficacy of CTX concomitant with RT observed in locally advanced disease also applies to recurrent and/or metastatic disease.

We administered CTX concomitant with second-line RT to 9 patients in our clinics, including 2 with carcinoma of the larynx with recurrence in tracheostomy, 2 with carcinoma of the larynx with neck metastasis, 2 with carcinoma of the lip with neck metastasis, 2 with carcinoma of the mouth base with recurrence, and 1 patient with carcinoma of the tongue base with neck metastasis. All of these patients had previously received curative treatments for primary disease. Second-line RT of these patients, who had SCHNC (except nasopharynx) and whose disease was considered inoperable and progressed under platinum-based or taxane regimens, including CT, or in whom these treatments were contraindicated, was planned conformally in 3-D considering tolerance doses of critical organs such as the spinal cord or mandibula. Four of 5 patients with neck metastases received $20 \mathrm{~Gy}, 1$ received $30 \mathrm{~Gy}, 1$ of 2 patients with carcinoma of the mouth base received $40 \mathrm{~Gy}, 1$ received $20 \mathrm{~Gy}$ and 2 patients with recurrence in tracheostomy received 70 Gy of RT. All patients received CTX concomitant with RT. Both treatments were well tolerated by the patients. Four patients had grade 2 and 5 patients had grade 3 radiation dermatitis according to NCI-CTCAE toxicity evaluation criteria (fig. 1 ). According to a review of the side effects of CTX by Galimont-Collen et al. [21], the most frequent adverse event reported in patients undergoing CTX treatment was grade $1(50 \%)$ followed by grade $2(14 \%)$ acne-like rash. Grade 3 and 4 toxicities are very rare. In parallel with these data, 5 patients in the present cohort had grade 1 and 4 had grade 2 acne-like rash (fig. 2 and fig. 3 ). Consistent with previous reports in the literature, common areas outside of the RT region where acne-like rash was observed included the upper back, upper chest wall and gluteal region. Xerosis cutis was observed in all patients in various grades. Painful paronychia-like reactions of the nails were observed in 2 of 5 patients receiving 6 cycles of CTX. Rarely observed hairy skin lesions and telangiectasia that are associated with the effects of EGFR inhibitors on capillary vessels were not seen in the present cohort. Concomitant CTX did not increase RT-associated toxicity in any of the patients. 
Mean post-treatment follow-up duration was 12.8 months. Mean survival was 19.8 months with a mean annual survival rate of $59.3 \%$. Vermoken et al. [22] performed a meta-analysis of studies including single-agent CTX or CTX combined with CT, and reported a mean survival of 5.9 months with CTX alone and 5.2-6.1 months with combination regimens. Although the present study included a relatively low number of patients, the mean survival time was evidently longer. However, we cannot make a clear comparison as there is no reference study in the literature to compare the present figures with. Recently, Balermpas et al. [23] performed a study in 7 patients with inoperable recurrence of SCHNC; second-line RT with concomitant CTX was administered but only toxicity assessment was done.

In the ongoing phase 2 NCT00226239 study, patients with stage 3-4 SCHNC are being randomized to CTX + RT or CT + RT arms following neoadjuvant TPF treatment. RTOG 0522 and RTOG 0234 studies are also ongoing CTX studies. RTOG 0522 is a phase 3 study designed to randomize naive patients with locally advanced SCHNC to $\mathrm{CT}+\mathrm{RT}$ and $\mathrm{CT}+\mathrm{RT}+\mathrm{CTX}$ arms. The results of these studies will clarify the importance of CTX in SCHNC treatment. Although CTX is approved for use in first-line treatment of recurrent and/or metastatic SCHNC in the USA and most European countries, it is approved for use in Turkey as a radiosensitizer concomitant with RT only in patients with locally advanced head and neck cancer in whom CT is contraindicated, except for carcinoma of the nasopharynx.

\section{Conclusion}

In our opinion, although CTX might appear to be an expensive treatment option, the addition of CTX to the treatment regimen will significantly reduce overall treatment costs since the sensitivity of disease to both CT and RT increases in patients with recurrent and/or metastatic SCHNC who receive CT or CRT as first-line treatment.

Table 1. Toxicity grading of radiation dermatitis according to the NCI-CTCAE

\begin{tabular}{|c|c|c|c|c|}
\hline Grade 1 & Grade 2 & Grade 3 & Grade 4 & Grade 5 \\
\hline $\begin{array}{l}\text { Faint erythema } \\
\text { or dry } \\
\text { desquamation }\end{array}$ & $\begin{array}{l}\text { Moderate to brisk } \\
\text { erythema; patchy moist } \\
\text { desquamation, mostly } \\
\text { confined to skin folds } \\
\text { and creases; moderate } \\
\text { edema }\end{array}$ & $\begin{array}{l}\text { Moist desquamation in } \\
\text { areas other than skin } \\
\text { folds and creases; } \\
\text { bleeding induced by } \\
\text { minor trauma or } \\
\text { abrasion }\end{array}$ & $\begin{array}{l}\text { Skin necrosis or } \\
\text { ulceration of full } \\
\text { thickness dermis; } \\
\text { spontaneous bleeding } \\
\text { from involved site }\end{array}$ & Death \\
\hline
\end{tabular}




\begin{tabular}{|c|c|c|c|}
\hline $\begin{array}{l}\text { Case Reports in } \\
\text { Oncoloys }\end{array}$ & \begin{tabular}{|l} 
Case Rep Oncol 2010;3:480-488 \\
DOI: 10.1159/000323204
\end{tabular} & $\begin{array}{l}\text { Published online: } \\
\text { December 17, } 2010\end{array}$ & $\begin{array}{l}\text { () } 2010 \text { S. Karger AG, Basel } \\
\text { ISSN 1662-6575 } \\
\text { www.karger.com/cro }\end{array}$ \\
\hline
\end{tabular}

Table 2. Toxicity grading of acne-like rash according to the NCI-CTCAE

\begin{tabular}{llll}
\hline Grade 1 & Grade 2 & Grade 3 & Grade 4 \\
\hline $\begin{array}{l}\text { Macular or papular } \\
\text { eruption or erythema } \\
\begin{array}{l}\text { without associated } \\
\text { symptoms }\end{array}\end{array}$ & $\begin{array}{l}\text { Localized follicular fistula } \\
\text { on }<50 \% \text { of body surface } \\
\text { area and pruritus }\end{array}$ & $\begin{array}{l}\text { Localized follicular fistula } \\
\text { on }>50 \% \text { of body surface } \\
\text { area and pruritus }\end{array}$ & $\begin{array}{l}\text { Exfoliative or } \\
\text { ulcerative } \\
\text { erythroderma }\end{array}$ \\
\hline
\end{tabular}

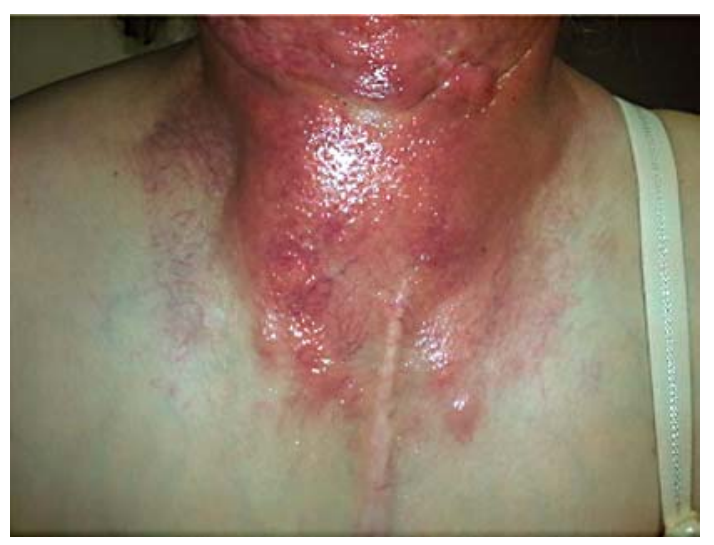

Fig. 1. Patient with RT-associated grade 3 toxicity.

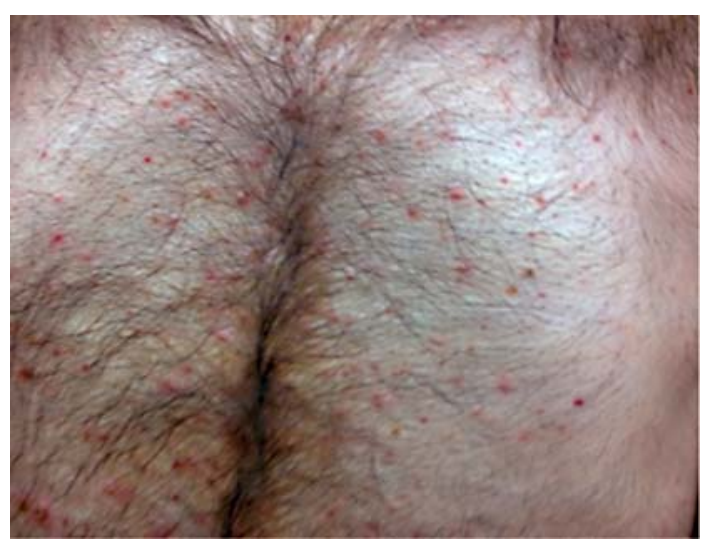

Fig. 2. Grade 1 acne-like rash. 


\begin{tabular}{c|l|l|l}
$\begin{array}{c}\text { Case Reports in } \\
\text { Oncology }\end{array}$ & $\begin{array}{l}\text { Case Rep Oncol 2010;3:480-488 } \\
\text { DOI: 10.1159/000323204 }\end{array}$ & $\begin{array}{l}\text { Published online: } \\
\text { December 17, 2010 }\end{array}$ & $\begin{array}{l}\text { O 2010 S. Karger AG, Basel } \\
\text { ISSN 1662-6575 } \\
\text { www.karger.com/cro }\end{array}$ \\
\hline
\end{tabular}

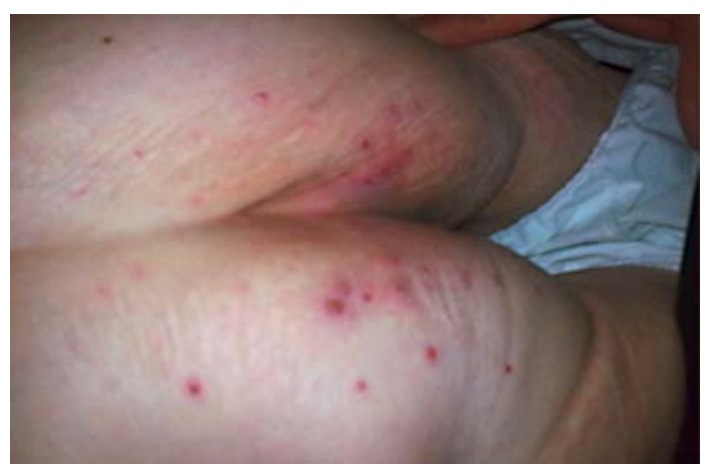

Fig. 3. Grade 2 acne-like rash.

\section{References}

1 Specenier PM, Vermorken JB: Recurrent head and neck cancer: current treatment and future prospects. Expert Rev Anticancer Ther 2008;8:375-391.

$\checkmark 2$ Leon X, Hitt R, Constenla M, et al: A retrospective analysis of the outcome of patients with recurrent and/or metastatic squamous cell carcinoma of the head and neck refractory to a platinum-based chemotherapy. Clin Oncol (R Coll Radiol) 2005;17:418-424.

-3 Vermorken JB, Trigo J, Hitt R, et al: Open label, uncontrolled, multicenter phase 2 study to evaluate the efficacy and toxicity of cetuximab as a single agent in patients with recurrent and/or metastatic squamous cell carcinoma of the head and neck who failed to respond to platinum-based therapy. J Clin Oncol 2007;25:21712177.

4 Bonner JA, Harari PM, Giralt J, et al: Radiotherapy plus cetuximab for squamous cell carcinoma of the head and neck. N Engl J Med 2006;354:567-578.

-5 Robert F, Ezekiel MP, Spencer SA, et al: Phase 1 study of antiepidermal growth factor receptor antibody cetuximab in combination with radiation therapy in patients with advanced head and neck cancer. J Clin Oncol 2001;19:3234-3243.

-6 Fan Z, Baselga J, Masui H, et al: Antitumor effect of anti-epidermal growth factor receptor monoclonal antibodies plus cis-diamminedichloroplatinum on well established A431 cell xenografts. Cancer Res 1993;53:4637-4642.

7 Herbst RS, Arguette MA, Shin D, et al: Phase II multicenter study of the epidermal growth factor receptor antibody cetuximab and cisplatin for recurrent and refractory squamous cell carcinoma of the head and neck. J Clin Oncol 2005;23:5578-5587.

8 Baselga J, Trigo JM, Bourhis J, et al: Phase II multicenter study of the antiepidermal growth factor receptor monoclonal antibody cetuximab in combination with platinum-based chemotherapy in patients with platinum refractory metastatic and/or recurrent squamous cell carcinoma of the head and neck. J Clin Oncol 2005;23:5568-5577.

9 Vermorken JB, Mesai R, Veg-Villagas ME, et al: Cetuximab in combination with cisplatin or carboplatin and 5fluorouracil in the first line treatment of patients with recurrent and/or metastatic squamous cell carcinoma of the head and neck (EXTREME). J Clin Oncol 2006, Abstract 5537.

10 Herhr T, Classen J, Belka C, et al: Reirridation alternating with docetaxel and cisplatin in inoperable recurrence of head and neck cancer: a prospective phase 1/2 trial. Int J Radiat Oncol Biol Phys 2005;61:1423-1431.

11 Vemorken JB: Medical treatment in head and neck cancer. Ann Oncol 2005;16:ii258-ii264.

12 Colevas AD: Chemotherapy options for patients with metastatic or recurrent squamous cell carcinoma of the head and neck. J Clin Oncol 2006;24:2644-2652.

13 Jacobs C, Lyman G, Velez-Garcia E, et al: A phase 3 randomized study comparing cisplatin and fluorouracil as single agents and in combination for advanced squamous cell carcinoma of the head and neck. J Clin Oncol 1992;10:257-263.

14 Gibson MK, Li Y, Murphy B, et al: Randomized phase 3 evaluation of cisplatin plus fluorouracil vs. cisplatin plus paclitaxel in advanced head and neck cancer (E1395): an intergroup trial of the Eastern Cooperative Oncology Group. J Clin Oncol 2005;23:3562-3567. 
15 Janinis J, Papadakou M, Xidakis E, et al: Combination chemotherapy with docetaxel, cisplatin and 5fluorouracil in previously treated patients with advanced/recurrent head and neck cancer: a phase 2 feasibility study. Am J Clin Oncol 2000;23:128-131.

16 Benasso M, Ponzanelli A, Merlona M, et al: Paclitaxel, cisplatin and 5-fluorouracil in recurrent squamous cell carcinoma of the head and neck: a phase 2 trial from an Italian cooperative group. Acta Oncol 2006;45:168174.

17 Ciardiello F, Tortora G: EGFR antagonists in cancer treatment. N Engl J Med 2008;358:1160-1174.

18 Caudell JJ, Sawrie SM, Spencer SA, et al: Locoregionally advanced head and neck cancer treated with primary radiotherapy: a comparison of the addition of cetuximab or chemotherapy and the impact of protocol treatment. Int J Radiat Oncol Biol Phys 2008;71:676-681.

19 Kramer NM, Horwitz EM, Cheng J, et al: Toxicity and outcome analysis of patients with recurrent head and neck cancer treated with hyperfractionated split-course reirradiation and concurrent cisplatin and paclitaxel chemotherapy from two prospective phase I and II studies. Head Neck 2005;27:406-414.

20 Milano MT, Vokes EE, Salama JK, et al: Twice-daily reirradiation for recurrent and second primary head-andneck cancer with gemcitabine, paclitaxel, and 5-fluorouracil chemotherapy. Int J Radiat Oncol Biol Phys 2005;61:1096-1106.

21 Galimont-Collen AF, Vos LE, Lavrijsen AP, et al: Classification and management of skin, hair, nail and mucosal side effects of epidermal growth factor receptor (EGFR) inhibitors, review. Eur J Cancer 2007;43:845851.

22 Vermorken JB, Herbst RS, Leon X, et al: Overview of the Efficacy of Cetuximab in Recurrent and/or Metastatic Squamous Cell Carcinoma of the Head and Neck in Patients Who Previously Failed Platinum-Based Therapies. American Cancer Society, 2008.

23 Balermpas P, Hambek M, Seitz O, Rödel C, Weiss C: Combined cetuximab and reirradiation for locoregional recurrent and inoperable squamous cell carcinoma of the head and neck. Strahlenther Onkol 2009;185:775781 . 